\title{
Accepted Record Flag
}

National Cancer Institute

\section{Source}

National Cancer Institute. Accepted Record Flag. NCI Thesaurus. Code C117038.

An indication or description of a record that is considered to be the accepted and final evaluation. 